\title{
The Impact of Money Supply on the Price: Evidence from China
}

\author{
Qishui Chi ${ }^{1}$ \\ ${ }^{1}$ Shantou University, Shantou, China \\ Correspondence: Qishui Chi, Shantou University, Shantou 515063, China. E-mail: chiqishui@163.com \\ Received: January 6, 2014 \\ Accepted: January 20, $2014 \quad$ Online Published: March 2, 2014 \\ doi:10.5430/rwe.v5n $1 \mathrm{p} 75$ \\ URL: http://dx.doi.org/10.5430/rwe.v5n1p75
}

\begin{abstract}
Different from the cointegration methodology flooding empirical literature, I resume debate regarding the impact of money supply on the overall price level by testing structural breaks of China's monetary aggregates from December 1999 to April 2012. The results show that the time series of logarithms of M0, M1 and M2 are all piecewise stationary with structural breakpoints being found at $1 \%, 5 \%$ or $10 \%$ critical levels. Furthermore, I find the overall price trends after structural changes can be estimated accurately according to the characteristics of these endogenous breaks. Such findings provide a new perspective for the effect evaluation of monetary policy.
\end{abstract}

Keywords: money supply, CGPI, structural change, endogenous breakpoints

\section{Introduction}

For over half a century the relationship between money supply and overall price level has attracted a considerable amount of empirical work in both economics and statistics literature. McCandless \& Weber (1995) worked out that the correlation coefficients for money growth and inflation were 0.925 to 0.958 . Chow (2002) drew a conclusion that the quantity theory of money effected in China from 1952 to 1993 . Chow \& Shen (2004) found the impulse responses of $\log$ price to innovations in M2 to be similar for China and USA. By analyzing the quarterly U.S. data from 1966:1 to 2001:3, Favara \& Giordani (2009) detected shocks to M2 had substantial and persistent effects on Consumer Price Index. Waingade (2011) found that India's M3 and the wholesale price index (WPI) were related and the former growth pushed WPI up rather than the growth of real national income. Different from the literature above, some studies such as Aksoy \& Piskorski (2006) argued that money supply had little impact on price. Digging into U.S. quarterly data from 1968:1 to 1998:2, Aksoy \& Piskorski (2006) drew a conclusion that the relationship between monetary aggregates and inflation had become weak since 1980s because of the flows of U.S. dollars abroad.

The empirical literature, studying the relationship between money supply and overall price level, has flooded by papers using cointegration technique or its derivatives such as Vector autoregression (VAR), the semi-structural VAR, Vector error correction (VEC), Granger causality test. For example, VAR method is used in Chow (2002), Chow \& Shen (2004), Favara \& Giordani (2009). Granger causality test is applied in Aksoy \& Piskorski (2006). Meanwhile, the difference operation is also widely used in these papers before analyzing with cointegration method or its derivatives because the original time series of money stock and overall price are often unit root processes. The conclusions of these literature, using cointegration method or its derivatives, are not reliable if the sequences of monetary aggregates are piecewise smooth and the overall price has a unit root. The reasons are expounded in detail as follows:

Firstly, the cointegration method and its derivatives can only be used when two or more time series are in the same order of integration. That is to say, the cointegration methodology doesn't work correctly if the overall price is a unit-root series, while money supply is a piecewise continuous one. Secondly, although the outcome of difference operation for a unit root series is as same as that for a piecewise stationary sequence, the missing information for short-term change in these two kinds of series is different. The difference operation will change the spectrum structure of data generation process (DGP) for a unit root sequence, while this can't happen for a piecewise stationary series in which breakpoints will be treated wrongly as singular values.

Therefore, structural change test should be carried out to judge whether a sequence is a real unit root process or not if Dickey-Fuller, Augmented Dickey-Fuller or Phillips-Perron test shows the sequence isn't a stationary one. My study shows that China's monetary aggregates are piecewise smooth rather than unit root series. The structural changes of 
monetary aggregates have great impacts on the overall price level. It's necessary to review literature about structural changes of macroeconomic time series because I attempt to investigate the relationship between money supply and the overall price level from a new perspective.

The viewpoint that most macroeconomic sequences are characterized by a stochastic rather than deterministic nonstationarity has dominated the academia of structural change until the seminal study of Perron (1989) published. Depending on Dickey \& Fuller $(1979,1981)$ method, Nelson \& Plosser (1982) found evidence in favor of the unit root hypothesis for 13 out of 14 U.S. annual macro series. It means that current shock would have a permanent effect on the long-run macroeconomic aggregate and the series has no tendency to revert to its equilibrium status or stable path. Applying the methods advocated by Dickey \& Fuller (1979), Phillips \& Perron (1988) or Campbell \& Mankiw (1987, 1988), a lot of study such as Wasserfallen (1986), Perron (1988) also affirmed that most macroeconomic series have a unit root. However, Perron (1989) argued that the unit root behavior could be due to the failure to account for structural change. Taking the Great Depression in 1929 and the Oil Crisis in 1973 as the points of exogenous structural breaks, Perron (1989) drew the conclusion that the majority of macroeconomic series were not characterized by the presence of a unit root.

The empirical work of Perron (1989) was seriously criticized by many scholars because of the common defect taking some events as breakpoints in advance. Zivot \& Andrews (1992) developed a methodology that transformed Perron's unit root test into an unconditional stability test. Utilizing its asymptotic critical values obtained by Monte Carlo simulation, Zivot \& Andrews (1992) couldn't reject the unit root hypothesis at the 5\% critical level for four Nelson and Plesser series. Meanwhile, Zivot \& Andrews (1992) reversed the unit root rejection in Perron (1989) for the postwar quarterly real GNP series.

By allowing the possibility of more potential breakpoints, Lumsdaine \& Papell (1997) extended Zivot and Andrews' endogenous break methodology to a two-break alternative. After reexamining the Nelson and Plosser data, Lumsdaine \& Papell (1997) found the 7 series rejected the unit root null hypothesis at the 5\% level, and 9 series against the null at the $10 \%$ level. In other words, Lumsdaine \& Papell (1997) found more evidence against the null hypothesis than that of Zivot \& Andrews (1992), but less than Perron's.

The problem for automatic identification of endogenous breakpoints number in a given time series has not been completely solved so far, but there are some kinds of models being put forward to get some breaks of time series. Perron (1989) and Zivot \& Andrews (1992) established the crash model (model A), the changing growth model (model B) and the both changing model (model C). By considering the possibility that two endogenous breakpoints occurred over the relevant time period, Lumsdaine \& Papell (1997) brought forward to model AA, CA and CC to reexamine the unit root hypothesis for the Nelson and Plosser data. Thence, the empirical study such as Ben-David, Lumsdaine \& Papell (2003), Papell \& Prodan (2007) using model AA, CA and CC to test endogenous breakpoints of time series has become prevalent. Considering the AA, CA, and CC model couldn't fully describe the characteristics of China's import and export time series, Wang, etc. (2009) applied more alternative models (model BB, AB, and CB) for two-break test.

Besides the literature Ben-David, Lumsdaine \& Papell (2003), Wang, etc. (2009) mentioned above, there are many other papers such as Kruse (2009) doing empirical study of breakpoints of economic time series in recent years. Applying the two-endogenous breakpoints models, Ben-David, Lumsdaine \& Papell (2003) did multi-break test on the output growth paths for the 16 industrialized countries from 1870 to 1990. It showed the unit root hypothesis had been rejected for around $75 \%$ of the countries. Most of the countries exhibited faster growth after their second breakpoints than during the period preceding the first breakpoints. Wang, etc. (2009) brought to light that China's export was a piecewise stationary series with many breakpoints correlated to big events during the period 1981:01-2006:12.

I investigate the possible impact of structural changes of monetary aggregates on the overall price level in China by analyzing the relevant monthly data from 1999:12 to 2012:04. The plan of the paper is as follows. Section II demonstrates the mechanism of the price impact generated by structural changes of monetary aggregates. Meanwhile, the endogenous breakpoints test methods are also set forth in this part. Using the bootstrap technique, Section III calculates the critical values for multi-break test models with 149 samples. Section IV does breakpoints test for the structural changes of logarithms of M0, M1 and M2. Section V investigates what happened to CGPI after the appearance of each structural breakpoint of money supply. Section VI draws conclusions containing suggestions for future research. 


\section{Models and Methodology}

According to the quantity theory of money, the relation for overall price and money stock is as follows:

$$
P \equiv \frac{M V}{Q} \equiv\left(\frac{V}{Q}\right) M \equiv k M
$$

where $P, M, V, Q$ refer to the price level, money supply, the velocity of money, real output respectively.

I assume that the time series of money stock is piecewise stationary. Let the observed data of money supply be $M=\{\operatorname{Mon}(1), \operatorname{Mon}(2), \ldots, \operatorname{Mon}(N)\}$. Suppose there are $q$ independent segments $s_{1}, s_{2}, \ldots, s_{q}$ corresponding to models $\operatorname{Mod}^{\left(s_{1}\right)}, \operatorname{Mod}^{\left(s_{2}\right)}, \operatorname{Mod}^{\left(s_{3}\right)}, \ldots, \operatorname{Mod}^{\left(s_{q}\right)} . \operatorname{Mod}^{\left(s_{m}\right)}$ is an autoregressive model with the order $h_{m}$, where $m=1,2,3, \ldots, q$. The data from the segment are generated according to:

$$
\operatorname{Mon}(n)=-a_{1}(n) \operatorname{Mon}(n-1)-a_{2}(n) \operatorname{Mon}(n-2)-\ldots-a_{p_{m}}(n) \operatorname{Mon}\left(n-h_{m}\right)+e(n)
$$

where the $e(n)$ is a zero-mean white noise variable whose variance is $\sigma_{m}^{2}$. I denote the breakpoints where structural changes happen with $\lambda_{1}, \lambda_{2}, \ldots, \lambda_{q-1}$. According to Djurić, Kay \& Boudreaux-Bartels(1992), the desired parameters can be obtained from the following equation:

$$
\left(\hat{q}, \hat{J}_{q-1}, \hat{H}_{q}\right)=\arg \min _{k, j_{k-1}, P_{k}}\left\{\frac{1}{N-k} \times\left[-\sum_{i=1}^{k} \sum_{l=\lambda_{i-1}+1}^{\lambda_{i}-1} \ln f\left(\operatorname{Mon}[l] \mid \operatorname{Mon}_{\lambda_{i-1}, l-1, p_{k}}\right)+\ln \frac{\prod_{l=1}^{k-1}(N-k-l)}{(k-1) !}+k \ln (H+1)\right]\right\}
$$

where $k \in(1,2, \cdots, Q)$. Thus segments' number $q$, breakpoints $J_{q-1}=\left[\lambda_{1}, \lambda_{2}, \ldots \lambda_{q-1}\right]$, autoregressive models' orders $H_{q}=\left[h_{1}, h_{2}, \ldots, h_{q}\right]$ could be estimated.

Suppose the time series of monetary aggregate is piecewise stationary, the stable money supply would generally result in stable rather than dramatic change of the overall price level. By contrary, the breakpoint $\lambda_{x+1}$ between $s_{x}$ and $s_{x+1}$ means the statistical characteristics of time series $M$ has changed and the shift will make the variable $P$ fluctuate dramatically. Consequently, it is reasonable and important to check out the breakpoints of time series $M$ to estimate the trend of the overall price level after the structural change occurs.

The theoretical foundation of the model AA, CC and CA is based on the one-break test brought forward by Zivot \& Andrews (1992). The null hypothesis for three models A, B and C in Zivot \& Andrews (1992) is:

$$
y_{t}=\mu+y_{t-1}+e_{t}
$$

where $\varepsilon_{t}$ is a zero-mean stationary innovation. The alternative hypothesis stipulates that the data generating process can be represented by a trend-stationary process with a one-time break in the trend occurring at an unknown date. Three versions of alternative models considered in Zivot \& Andrews (1992) are:

$$
\begin{array}{ll}
\operatorname{model} \mathrm{A}: & y_{t}=\hat{\mu}^{A}+\hat{\theta}^{A} D U_{t}(\hat{\lambda})+\hat{\beta}^{A} t+\hat{\alpha}^{A} y_{t-1}+\sum_{j=1}^{k} \hat{c}_{j}^{A} \Delta y_{t-i}+\hat{e}_{t}, \\
\operatorname{model} \mathrm{B}: & y_{t}=\hat{\mu}^{B}+\hat{\beta}^{B} t+\hat{\gamma}^{B} D T_{t}^{*}(\hat{\lambda})+\hat{\alpha}^{B} y_{t-1}+\sum_{j=1}^{k} \hat{c}_{j}^{B} \Delta y_{t-i}+\hat{e}_{t}, \\
\operatorname{model~C}: & y_{t}=\hat{\mu}^{C}+\hat{\theta}^{C} D U_{t}(\hat{\lambda})+\hat{\beta}^{C} t+\hat{\gamma}^{C} D T_{t}^{*}(\hat{\lambda})+\hat{\alpha}^{C} y_{t-1}+\sum_{j=1}^{k} \hat{c}_{j}^{C} \Delta y_{t-i}+\hat{e}_{t},
\end{array}
$$

where $D U_{t}$ and $D T_{t}$ are dummy variables. $D U_{t}(\hat{\lambda})=1$ and $D T_{t}^{*}(\hat{\lambda})=t-T \lambda$ when $t>T \lambda ;($ Note 1$) D U_{t}(\hat{\lambda})=0 ;$ $D U_{t}(\hat{\lambda})=0$ when $t \leq T \lambda$ 
The $k$ extra regressors in the equations above are added to eliminate possible nuisance-parameter dependencies in the limit distributions of the test statistics caused by temporal dependence in the disturbances. The number of $k$ is determined by a test of the significance of the estimated coefficients $\hat{c}_{k}^{i}$. (Note 2) Working backward from $k=k$, I choose the $1^{\text {st }}$ values of $k$ such that the t-statistics on $\hat{c}_{k}^{i}$ is greater than 1.6 which also being chosen by Zivot $\&$ Andrews (1992), Perron (1989), Ben-David, Lumsdaine \& Papell (2003) and Papell \& Prodan (2007).

After doing the Ordinary Least Square (OLS) regression for the three equations respectively for every possible endogenous breakpoint $T B \in[2, T-1]$, I could obtain the estimated values of $\hat{\alpha}^{i}$ and one-side $t$ statistic $t_{\hat{\alpha}^{i}}(\lambda)$ for testing the null hypothesis $\alpha=1$. Let $\hat{\lambda}_{\mathrm{inf}}^{i}$ denote the minimizing values for model A, B or C, the null hypothesis would be rejected if the following expressions come into existence:

$$
\inf _{\lambda \in \Lambda} t_{\hat{\alpha}^{\prime}}(\lambda)<K_{\mathrm{inf}, \alpha}^{i}, \quad i=A, B, C
$$

where $K_{\mathrm{inf}, \alpha}^{i}$ denotes the asymptotic distribution of $\inf _{\lambda \in \Lambda} t_{\hat{\alpha}^{i}}(\lambda)$ in various significance level. (Note 3) Let $k=0$, and $T \rightarrow \infty$, then

$$
\inf _{\lambda \in \Lambda} t_{\hat{\rho}^{i}}(\lambda) \stackrel{d}{\rightarrow} \inf _{\lambda \in \Lambda}\left(\int_{0}^{1} W^{i}(\lambda, r)^{2} d r\right)^{-1 / 2} \times\left(\int_{0}^{1} W^{i}(\lambda, r) d w(r)\right), \quad i=A, B, C
$$

Lumsdaine \& Papell (1997) did the ADF unit root test according to the following equation:

$$
y_{t}=\Xi^{\prime} Z_{t-1}+\varepsilon_{t}
$$

where $Z_{t-1}=\left[Z_{t}^{1}, 1,\left(y_{t}-\bar{\mu}_{0} t\right), t+1, D U 1_{t+1}, D U 2_{t+1}, D T 1_{t+1}, D T 2_{t+1}\right]^{\prime}$, and $\Xi$ denotes a transformed parameter vector. Similar to the case of one-break model, the values of dummy variables are determined by breaks $T B_{n}, D U n_{t}=1$ and $D T n_{t}=t-T B_{n}$ as long as $t>T B_{n} ; i=A, B, C$ otherwise. The equation $\lambda=T B_{n} / T$ means the locations of two breakpoints which are neither identical nor conjoint. The values range $\Lambda$ of $\lambda=\left[\lambda_{1}, \lambda_{2}\right]$ is a close subset $(0,1) \times(0$, 1). The null hypothesis that the original time series is a piecewise trend stationary process should be $\alpha=0$ because DGP transformed from original time series into one order difference form.

I can acquire $\hat{\alpha}$ and its $t$-statistics by carrying out the OLS regression in turn with every $\lambda=\left[\lambda_{1}, \lambda_{2}\right]$ in $\Lambda$ for model $i$. $\lambda$ corresponding the minimum values of $t$-statistics are most possibly to be breakpoints. Then, by definition I get the following expression:

$$
\hat{\lambda}_{\text {inf }}^{i}=\left(\hat{\lambda}_{\text {linf }}^{i}, \hat{\lambda}_{2 \text { inf }}^{i}\right), t\left[\hat{\lambda}_{\text {inf }}^{i}\right]=\inf _{\lambda \in \boldsymbol{\Lambda}} t_{\hat{\alpha}^{i}}(\boldsymbol{\lambda}), i=A A, C C, C A
$$

If

$$
t\left[\hat{\lambda}_{\mathrm{inf}}^{i}\right]<k_{\mathrm{inf}, \beta}^{i},
$$

the null hypothesis would be rejected. That is to say, the alternative one that the time series is a segment-trend-stationary sequence would be accepted. (Note 4)

\section{Critical Values Generated from Monte Carlo Simulation}

Although Lumsdaine \& Papell (1997) figured out the critical values of multi-break test for 125 observations, I can't use them because there are 149 observations for each time series of monetary aggregates in this article. For the accuracy of the two-break test, I simulate the critical values for exact sample size $(T=149)$ through Monte Carlo Method. 
I need to generate the discrete distribution of $\inf _{\lambda \in \Lambda} t_{\hat{\alpha}^{i}}(\lambda)$ to get the critical values mentioned above. The key steps for obtaining the distribution are as follows:

(1) To get mathematical sets $\left\{\tilde{y}_{t}^{j}\right\}_{j=1}^{J}$ for unit root series with $T$ samples through random generation;

(2) To gain the values of $t_{j}\left[\hat{\lambda}_{\text {inf }}^{i}\right]$ after regressing for model AA, CC and CA with $\left\{\tilde{y}_{t}\right\}$ generated by the first step;

(3) To obtain the discrete distribution $\left\{t_{j}\left[\hat{\lambda}_{\text {inf }}^{i}\right]: j=1, \ldots J\right\}$ of $\inf _{\lambda \in \wedge} t_{\hat{\alpha}^{\prime}}(\lambda)$ and its corresponding significant level of one-side-test critical values.

The calculating steps of the Monte Carlo simulation overcoming the possible correlation of the time series are as follows:

(1) To acquire the coefficients $\phi_{\mathrm{i}}(\mathrm{i}=1,2, \ldots, \mathrm{p}), \theta_{\mathrm{j}}(\mathrm{j}=1,2, \ldots, \mathrm{q})$ and standard deviation of residual $e$ by fitting one-order difference of time series being tested with the $\operatorname{ARMA}(\mathrm{p}, \mathrm{q})$ model, that is, let $A(L) \Delta y_{t}=B(L) \varepsilon_{t}$, where $\varepsilon_{t} \sim$ i.i.d. $N\left(0, \sigma^{2}\right)$ and $L$ is a lag operator;

(2) To generate the unit-root series $\left\{\tilde{y}_{t}\right\}$ by substituting normal pseudo random numbers with a stand deviation $\sigma=e$ and a zero mean into the ARMA model estimated;

(3) To get mathematical sets $\left\{\tilde{y}_{t}^{j}\right\}_{j=1}^{J}$ by repeating the calculating procedures for $J$ times.

Lumsdaine \& Papell (1997) got the critical values for 125 observations by taking the equation $\Delta \mathrm{y}_{\mathrm{t}}=\varepsilon_{\mathrm{t}}$ as DGP. In addition, Lumsdaine and Papell's study drew a conclusion that there weren't significant difference among the three ways generating the critical values for multi-break test after the other two methods were discussed.

Tons of calculation is needed to fit every single time series if the ARMA model is applied to get critical values. Therefore, I use the equation $\Delta \mathrm{y}_{\mathrm{t}}=\varepsilon_{\mathrm{t}}$ as DGP for generating random series and thus getting critical values. The main steps are as follows:

(1) Letting the initial value $\mathrm{y}_{1}=0$ and taking $\Delta \mathrm{y}_{\mathrm{t}}=\varepsilon_{\mathrm{t}}$ as DGP, I generate time series $\left\{\mathrm{y}_{\mathrm{t}}\right\}$ with 149 data by random;

(2) I obtain $t\left[\hat{\lambda}_{\text {inf }}^{i}\right]$ by substituting $\left\{\mathrm{y}_{\mathrm{t}}\right\}$ into Model AA, CC and CA and then by doing recursive regressions for all of possible breakpoints at $\lambda_{1}, \lambda_{2} \in[0.1,0.9]$;

Ultimately, I get the critical values which are shown in table 1 by repeating the steps for 10,000 times.

Table 1. Critical values for multi-break models

\begin{tabular}{cccccccccccc}
\hline Model & $1 \%$ & $2.50 \%$ & $5 \%$ & $10 \%$ & $15 \%$ & $50 \%$ & $85 \%$ & $90 \%$ & $95 \%$ & $97.5 \%$ & $99 \%$ \\
\hline AA & -6.6716 & -6.3952 & -6.1345 & -5.8695 & -5.6780 & -4.9740 & -4.3172 & -4.1524 & -3.9078 & -3.6757 & -3.3833 \\
CC & -7.2578 & -6.9734 & -6.7526 & -6.4694 & -6.3063 & -5.6059 & -4.9402 & -4.7801 & -4.5542 & -4.3434 & -4.0976 \\
CA & -7.0800 & -6.7662 & -6.5161 & -6.2335 & -6.0458 & -5.3173 & -4.6367 & -4.4612 & -4.1984 & -3.9621 & -3.6893 \\
\hline
\end{tabular}

Note: 10,000 repetitions under the null hypothesis $\Delta \mathrm{y}_{\mathrm{t}}=\varepsilon_{\mathrm{t}}$ with 149 observations.

As the appendix indicates, I get the histograms and density plots of $\inf _{\lambda \in \Lambda} t_{\hat{\alpha}^{\prime}}(\lambda)$ for six models including model AA, $\mathrm{CC}$ and CA simultaneously. 


\section{Empirical Results of Breakpoints Tests}

\subsection{Data}

I choose variables of the overall index of Corporate Goods Price Indices (CGPI), currency in circulation (M0), narrow money (M1) and broad money (M2) to investigate the impact of structural changes of monetary aggregates on price in China. The time period for all of series is from December 1999 to April 2012. The monthly data of CGPI, M0, M1 and M2 come from China's Central Bank.

Time series observed at monthly frequencies often exhibit cyclical tracks that recur every month. In order to remove these cyclical seasonal movements, and then extract the underlying trend component of time series, it's essential to make seasonal adjustments for the original data. Apparently, the time series of China's monetary aggregates have the characteristics of seasonal variation, particularly for the currency in circulation. Therefore, it is of great necessities to adjust the original series.

The additive modus for seasonal adjustment should be used if the seasonal component in economic series is constant. On the other hand, the multiplicative one should be employed when the seasonal component shows the characteristic of changing proportionally with the trend. The later one should be chosen in this article because the seasonal factors in China's monetary aggregates vary with the trend. Recently, X-12-ARIMA which includes essentially all the capabilities of X-11-ARIMA and X-11 is developed. For the advantages of the X-12-ARIMA providing many enhancements in model selection and diagnostics, I employ this method to remove the seasonal factor in this article.

Finally, I take the natural logarithms for the time series of China's monetary aggregates adjusted by X-12-ARIMA method to eliminate the influence of heteroscedasticity.

\subsection{Unit Root Test}

It is required to test the stationarity of time series before performing the unit root test with structural breaks. The unit root test with structural breaks makes no sense if the original series is stationary.

The ADF test for $\alpha=0$ is processed for the three seasonal adjusted series $\log$ M0, log M1 and $\log$ M2 in the following equation:

$$
\Delta y_{t}=\mu+\beta t+\alpha y_{t-1}+\sum_{i=1}^{k} c_{i} \Delta y_{t-i}+\varepsilon_{t}, \quad \varepsilon_{t} \sim \operatorname{iid} N\left(0, \sigma^{2}\right)
$$

The lag length $k$ is determined by Schwarz Information Criterion (SIC). The results are presented in the following table:

Table 2. ADF unit root test results

\begin{tabular}{ccccccc}
\hline Series & Test form & $t_{\alpha}$ & $1 \%$ level & $\begin{array}{c}\text { Critical value } \\
5 \% \text { level }\end{array}$ & $10 \%$ level & $\begin{array}{c}\text { Lag } \\
\text { length(SIC) }\end{array}$ \\
\hline M0 & $(\mathrm{c}, \mathrm{t}, 0)$ & -2.7578 & -4.0264 & -3.4430 & -3.1462 & 11 \\
M1 & $(\mathrm{c}, \mathrm{t}, 0)$ & -1.4729 & -4.0213 & -3.4405 & -3.1447 & 0 \\
M2 & $(\mathrm{c}, \mathrm{t}, 0)$ & -2.2191 & -4.0221 & -3.4409 & -3.1450 & 2 \\
D(M0) & $(\mathrm{c}, 0,1)$ & $-2.6934^{\mathrm{c}}$ & -3.4785 & -2.8826 & -2.5781 & 10 \\
D(M1) & $(\mathrm{c}, 0,1)$ & $-13.114^{\mathrm{a}}$ & -3.4752 & -2.8811 & -2.5773 & 0 \\
D(M2) & $(\mathrm{c}, 0,1)$ & $-6.9323^{\mathrm{a}}$ & -3.4755 & -2.8813 & -2.5774 & 1 \\
D(M0,2) & $(\mathrm{c}, 0,2)$ & $-9.7017^{\mathrm{a}}$ & -3.4789 & -2.8827 & -2.5782 & 10 \\
\hline
\end{tabular}

Note: $\mathrm{a}, \mathrm{b}, \mathrm{c}$ denote the rejection of null hypothesis at the $1 \%, 5 \%$, and $10 \%$ critical levels respectively.

Table 2 shows that $\log$ M0, $\log$ M1 and $\log$ M2 are integrated of order one or two. Therefore, it is essential to do structural breakpoints tests.

\subsection{One-Break Test}

Three versions of Zivot and Andrews' one-break test, model A, B, and C, are employed to investigate the unit-root hypothesis for the three time series of China's monetary aggregates. Table 3 shows the percentage points of the asymptotic distribution of $\inf _{\lambda \in \wedge} t_{\hat{\alpha}^{\prime}}(\lambda)$ for the three models by the study of Zivot \& Andrews (1992).

Then, according to the procedure outlined in previous section and Table 3, I obtain the results of one-break test. 
Table 3. The results of one-breakpoint test

\begin{tabular}{cccccccccc}
\hline Series & Model & $T B$ & $\hat{\alpha}$ & $t_{\hat{\alpha}}$ & $\hat{\theta}$ & $t_{\hat{\theta}}$ & $\hat{\gamma}$ & $t_{\hat{\gamma}}$ & $k$ \\
\hline \multirow{4}{*}{ M0 } & A & $2010: 02$ & -0.5274 & $\mathbf{- 5 . 1 0 3 5}^{\mathbf{b}}$ & 0.0352 & 4.2315 & & & 12 \\
& B & $2005: 07$ & -0.6447 & $\mathbf{- 4 . 1 7 6 9}^{\mathbf{c}}$ & & & 0.0012 & 3.0928 & 12 \\
& C & $2005: 01$ & -0.6559 & -4.3486 & -0.0124 & -1.5133 & 0.0012 & 2.8563 & 12 \\
& A & $2009: 02$ & -0.2345 & $\mathbf{- 5 . 7 3 9 6}^{\mathbf{a}}$ & 0.0241 & 4.8894 & & & 11 \\
M1 & B & $2005: 03$ & -0.0822 & -2.7746 & & & 0.0001 & 0.8731 & 5 \\
& C & $2004: 05$ & -0.0909 & -3.0904 & -0.0069 & -1.5595 & $-2.4 \mathrm{E}-06$ & -0.0170 & 5 \\
& A & $2009: 01$ & -0.2215 & $\mathbf{- 6 . 1 0 9 8}^{\mathbf{a}}$ & 0.0186 & 5.8476 & & & 11 \\
M2 & B & $2007: 12$ & -0.1546 & -3.3867 & & & 0.0003 & 2.5966 & 11 \\
& C & $2009: 01$ & -0.2113 & -4.5035 & 0.0189 & 5.7028 & $-4.8 \mathrm{E}-05$ & -0.3440 & 11 \\
\hline
\end{tabular}

Note: $\mathrm{a}, \mathrm{b}, \mathrm{c}$ denote the rejection of null hypothesis at the $1 \%, 5 \%$, and $10 \%$ critical levels respectively.

The test results for model A, which only has the intercept drift being considered, indicate that the null hypothesis can be rejected at the $5 \%$ critical level for $\mathrm{M} 0$ and the $1 \%$ level for $\mathrm{M} 1$ and $\mathrm{M} 2$. There are three structural breakpoints occurring at 2010:02, 2009:01 and 2009:02. The coefficients for the dummy variables of intercept item are all positive numbers. Therefore, it's evident from the test results that the central bank tends to ease its monetary policy to stimulate economic recovery during the financial crisis.

Suppose structural changes take place in the slope, model B should be selected for test. The results demonstrate that the null hypothesis can't be rejected at the 5\% critical level for the three monetary aggregates, which indicates that there isn't any event causing only a drastic growth rate change in China's money supply from 1999:12 to 2012:04.

If structural changes occur in both intercept and slope, model $\mathrm{C}$ is appropriate for testing. The test results reveal that there are not structural changes in China's monetary aggregates during the period of 1999:12-2012:04. That is to say, the event making money supply change dramatically in the intercept and the growth rate at the same time doesn't exist during this period.

\subsection{Multi-Break Test}

In the case of China's money supply, there are many affecting events happened during 1999:12-2012:04. Theoretically, more than one event resulting in structural change may exist. Therefore, the models in Lumsdaine and Papell (1997) are also employed to investigate structural changes of China's money supply. Furthermore, I use the critical values which are given in Table 1 for multi-break models with 149 observations. The results for the three versions of multi-breakpoint test are present as follows:

Table 4. The results of multi-breakpoint test

\begin{tabular}{|c|c|c|c|c|c|c|c|c|}
\hline Series & Model & $\hat{\alpha}$ & $T B_{n}$ & $\hat{\theta}_{1}, \hat{\theta}_{2}$ & $t_{\hat{\theta}_{1}}, t_{\hat{\theta}_{2}}$ & $\hat{\gamma}_{1}, \hat{\gamma}_{2}$ & $t_{\hat{\gamma}_{1}}, t_{\hat{\gamma}_{2}}$ & $k$ \\
\hline \multirow{5}{*}{ M0 } & AA & -0.7683 & 2007:02 & 0.0366 & 4.9284 & & & 12 \\
\hline & & $\left(-7.2171^{a}\right)$ & 2010:02 & 0.0536 & 6.3221 & & & \\
\hline & $\mathrm{CC}$ & -0.8706 & 2007:02 & 0.0362 & 3.8990 & 0.0004 & 0.8786 & 12 \\
\hline & & $(-4.9089)$ & 2010:04 & 0.0454 & 3.6241 & 0.0001 & 0.1667 & \\
\hline & CA & -0.8386 & 2010:02 & 0.0512 & 5.6439 & 0.0005 & 0.7512 & 12 \\
\hline \multirow{7}{*}{ M1 } & & $(-5.9103)$ & 2007:02 & 0.0401 & 4.5661 & & & \\
\hline & AA & -0.2417 & 2003:05 & 0.0078 & 1.9963 & & & 11 \\
\hline & & $\left(-5.9646^{d}\right)$ & 2009:02 & 0.0293 & 5.3052 & & & \\
\hline & $\mathrm{CC}$ & -0.1490 & 2010:04 & -0.0063 & -0.9183 & -0.0038 & -5.3117 & 1 \\
\hline & & $(-3.4907)$ & 2008:06 & -0.0156 & -2.6132 & 0.0023 & 4.5358 & \\
\hline & CA & -0.2437 & 2004:05 & -0.0045 & -1.0152 & -0.0004 & -2.1335 & 11 \\
\hline & & $(-5.9469)$ & 2009:02 & 0.0288 & 4.9699 & & & \\
\hline M2 & AA & -0.2477 & 2009:01 & 0.0243 & 6.7201 & & & 11 \\
\hline
\end{tabular}




\begin{tabular}{lccrrrrr} 
& $\left(-\mathbf{- 6 . 8 4 6 7}^{\mathbf{a}}\right)$ & $2002: 07$ & 0.0070 & 3.0102 & & & \\
$\mathrm{CC}$ & -0.1737 & $2008: 12$ & 0.0210 & 6.8676 & -0.0002 & -1.9301 & 1 \\
& $(-5.6362)$ & $2004: 06$ & -0.0058 & -2.4930 & -0.0002 & -2.3859 & \\
$\mathrm{CA}$ & -0.2794 & $2004: 05$ & -0.0080 & -3.2046 & -0.0004 & -3.6003 & 11 \\
& $\left(-\mathbf{- 7 . 4 5 1 3}^{\mathrm{a}}\right)$ & $2009: 01$ & 0.0254 & 6.7980 & & & \\
\hline
\end{tabular}

Note: the values in the brackets are t-statistics of $\hat{\alpha}$.

In Table 4 , the letters $\mathrm{a}, \mathrm{b}, \mathrm{c}, \mathrm{d}$ denote $1 \%, 2.5 \%, 5 \%$ and $10 \%$ levels respectively. The numbers in the first line for each model represent the happening dates of breakpoints $T B_{1}$ and the corresponding values of $\hat{\theta}_{1}, t_{\hat{\theta}_{1}}, \hat{\gamma}_{1}, t_{\hat{\gamma}_{1}}$. The data in the second line for every single model denote the days markings for breakpoints $T B_{2}$ and their corresponding values of $\hat{\theta}_{2}, t_{\hat{\theta}_{2}}, \hat{\gamma}_{2}, t_{\hat{\gamma}_{2}}$.

For China's currency in circulation, the evidence against the unit root null is found in model AA, which illustrates the first breakpoint appearing at 2007:02 and the second one at 2010:02. The test results that $\theta_{1}=0.0366$ and $\theta_{2}=$ 0.0536 coincide with the historical facts that the surplus of liquidity in the year of 2007 and the inflation in 2010 in China.

As to narrow money, although no evidence against the null at the 5\% critical level is found in the three versions of two-break test, model AA can reject the unit root null at the 10\% level with its first break in the intercept at 2003:05 and its second break at 2009:02.

When it comes to broad money, the results from model AA and CA reject the unit root null at the $1 \%$ critical level. For model AA, there are two breakpoints occurring at 2009:01 and 2002:07 with $\theta_{l}=0.0243$ and $\theta_{2}=0.0070$. The former breakpoint illustrates that the speed-up of money supply to stimulate China's economy after the breakout of global financial crisis. The latter one demonstrates that the central bank wanted to ease its monetary policy in the summer of 2002. For example, there were two conference held by China's central bank to strengthen financial support for enterprises in June and July, 2002. For Model CA, the result suggests that the null for China's broad money can be rejected at the $1 \%$ critical level with its breakpoints occurring at 2004:05 and 2009:01. For the breakpoint occurring at 2004:05, both the estimated values of $\theta_{1}$ and $\gamma_{2}$ are negative. In the middle of the year 2004, the monetary policy tended to prevent inflation which let the supply of broad money drift downward in the intercept and the growth rate fall synchronously.

\section{The Impact of Structural Change on the Price}

Table 5 indicates eight breakpoints gotten by one-break and two-break test at $1 \%, 5 \%$ or $10 \%$ critical level. I use Arabic numbers 1 to 8 to denote the breakpoints being found.

Table 5. The breakpoints of the structure changes

\begin{tabular}{|c|c|c|c|c|}
\hline \multirow[b]{2}{*}{ Breakpoint } & \multirow[b]{2}{*}{$\begin{array}{l}\text { Monetary } \\
\text { aggregate }\end{array}$} & \multicolumn{2}{|c|}{ Significant level } & \multirow[b]{2}{*}{ Date for break } \\
\hline & & $\begin{array}{c}\text { One-break } \\
\text { test }\end{array}$ & $\begin{array}{c}\text { Two-break } \\
\text { test }\end{array}$ & \\
\hline 1 & M2 & & $99 \%(\mathrm{AA})$ & 2002:07 \\
\hline 2 & M1 & & $90 \%(\mathrm{AA})$ & 2003:05 \\
\hline 3 & M2 & & $99 \%(\mathrm{CA})$ & 2004:05 \\
\hline 4 & M0 & $90 \%(\mathrm{~B})$ & & 2005:07 \\
\hline 5 & M0 & & $99 \%(\mathrm{AA})$ & 2007:02 \\
\hline 6 & M2 & $99 \%(\mathrm{~A})$ & $\begin{array}{c}99 \%(\mathrm{AA}, \\
\mathrm{CA})\end{array}$ & 2009:01 \\
\hline 7 & M1 & $99 \%(\mathrm{~A})$ & $90 \%(\mathrm{AA})$ & 2009:02 \\
\hline 8 & M0 & $95 \%(\mathrm{~A})$ & $99 \%(\mathrm{AA})$ & 2010:02 \\
\hline
\end{tabular}

Note: the specific inspection model in brackets.

In order to validate the impact of the structure change of money supply on the overall price level, I investigate what happened to CGPI after the appearance of each structural breakpoint of money supply with the intuitive comparison 
method and the Fisher exact test.

\subsection{The Preliminary Verification}

For the convenience of intuitive analysis, I draw figure 2 which shows the curve of CGPI and the dates for eight structural breakpoints of monetary aggregates.

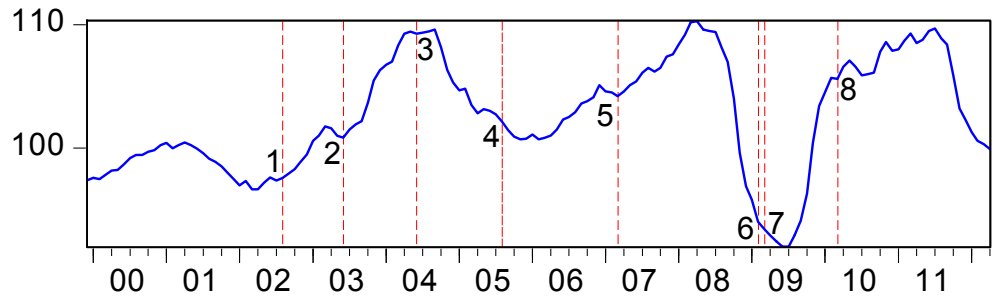

Figure 1. CGPI and the breakpoints of money supply

According to the values of $\hat{\theta}$ or $\hat{\gamma}$ corresponding to each break of M0, M1 and M2, CGPI would rise soon after the breakpoint 1,2, 4, 5, 6, 7 or 8 appeared if the structural change of money supply impacted CGPI effectively. For the same reason, CGPI would fall after the emergence of the $3^{\text {rd }}$ break. The figure 2 illustrates that the trend of CGPI accords with what mentioned above.

After the appearance of the $1^{\text {st }}$ breakpoint occurring at 2002:07, CGPI went up from the next month on. The coal, oil, and electricity index which was one of components of CGPI rose form 99.21 at 2002:07 to 109.85 at 2002:12 and kept up rising in the early of 2003. After the emergence of the $2^{\text {nd }}$ breakpoint at 2003:05, CGPI did not stop rising from the next month on until the appearance of the next break occurred at 2004:05. It's possible to make the wrong expectation that the CGPI's growth would be under control because of the consideration of the real estate regulation at that time, but I could get the correct answer that CGPI would goes up quickly after the appearance of this breakpoint according to the structural break test. After 2004:05 when the $3^{\text {rd }}$ break happened, the trend of CGPI changed from rising into declining because the values of $\hat{\theta}_{1}$ and $\hat{\gamma}_{1}$ for this break are both negative. The emergence of the $4^{\text {th }}$ break at 2005:07 indicates that the trend of CGPI falling since 2004:09 would come to an end and the consecutive rising of CGPI would happen soon because of the positive value of $\hat{\gamma}$. After the $5^{\text {th }}$ break occurring at 2007:02, CGPI would continue going upward. According to the figure 2, I know that CGPI kept going upward until 2008:04. After the $6^{\text {th }}$ and $7^{\text {th }}$ breaks occurring in the early 2009, CGPI would rise quickly soon. The structural change of narrow money or broad money at these two breaks changed the trend of CGPI. The last break happened at 2010:02 and its appearance made CGPI rise continuously for more than one year.

Thereby, the intuitive comparison above indicates that the structural changes of natural logarithms of monetary aggregates affect the overall price index. After the date for a structural break of money supply series, the overall price trend expected according to the characteristic of breakpoint is consistent with the real one. The preliminary verification results for our findings are show as following table.

Table 6 . The preliminary verification results

\begin{tabular}{|c|c|c|c|c|}
\hline \multirow{2}{*}{ Break } & \multirow{2}{*}{$\begin{array}{l}\text { The date } \\
\text { for a break }\end{array}$} & \multicolumn{2}{|c|}{ The price trend after a breakpoint } & \multirow{2}{*}{$\begin{array}{l}\text { Is } T T \text { consistent } \\
\text { with } R T\end{array}$} \\
\hline & & Break test result $(T T)$ & Real price trend $(R T)$ & \\
\hline 1 & 2002:07 & upward & CGPI began to rise from the next month on. & Yes \\
\hline 2 & 2003:05 & upward & $\begin{array}{l}\text { CGPI kept up rising until the appearance of } \\
\text { the next break. }\end{array}$ & Yes \\
\hline 3 & 2004:05 & downward & CGPI stopped rising and fell soon. & Yes \\
\hline 4 & 2005:07 & upward & $\begin{array}{l}\text { The falling trend of CGPI would end soon } \\
\text { and then began to rise dramatically. }\end{array}$ & Yes \\
\hline 5 & 2007:02 & upward & CGPI rose again from 2007:04 on. & Yes \\
\hline 6 & 2009:01 & upward & CGPI went up dramatically from 2009:06 on. & Yes \\
\hline 7 & 2009:02 & upward & CGPI went up dramatically from 2009:06 on. & Yes \\
\hline 8 & 2010:02 & upward & CGPI continued to rise. & Yes \\
\hline
\end{tabular}




\subsection{The Fisher Exact Test}

Although the preliminary verification above has its obvious advantage, I will use the Fisher exact test to re-validate the impact of money supply on the overall price level because the intuitive comparison method may lack preciseness in examination.

According to the occurring date of each breakpoint $T B$ of money supply, I can divided the data of CGPI into two kinds of groups denoted with $G_{j, b e f}$ and $G_{j, a f t}$. For each break $j$, the former group represents the mathematic set before the break presents itself and the later one means the set after the appearance of the breakpoint. Generally, the data of $G_{j, b e f}$ begins from the last round of CGPI fall or rise, and ends at breakpoint TB. The data of $G_{j, b e f}$ starts from $T B+1$ and stops at the end of next round of CGPI rise or fall. Moreover, the appropriate adjustment combined with business cycle and the structural change theory is necessary to determine the subsamples for a group.

Suppose the probability of CGPI positive growth after the breakpoint $T B$ is $\pi_{1}$. In other words, $X_{1}$ exhibiting how many months in which CGPI goes up after the break submits to the Bernoulli distribution with a $\pi_{1}$ mean. The null hypothesis of the Fisher exact test in this article is $H_{0}: \pi_{1}=\pi_{2}$ where $\pi_{2}$ denotes the probability of CGPI positive growth before the breakpoint $T B$

The null $\pi_{1}=\pi_{2}$ can also be expressed as follows:

$$
P\left(x_{1} \leq X_{1} \leq \min \left\{t, n_{1}\right\} \mid X_{1}+X_{2}=t\right)=\sum_{x_{1} \leq u \leq \min \left\{t, n_{1}\right\}} P\left(X_{1}=u \mid X_{1}+X_{2}=t\right)
$$

where

$$
P\left(X_{1}=u \mid X_{1}+X_{2}=t\right)=\frac{C_{n_{1}}^{u} C_{n_{2}}^{t-u}}{C_{n_{1}+n_{2}}^{t}}, \quad \max \left\{t-n_{2}, 0\right\} \leq u \leq \min \left(t, n_{1}\right)
$$

Thus the test statistics submit to a hypergeometric distribution. Then I can have the following fourfold table:

Table 7. Fourfold table for CGPI growth

\begin{tabular}{cccc}
\hline Group & Months (CGPI rises) & Months (otherwise for CGPI) & Total \\
\hline$G_{j, a f t}$ & $u$ & $n_{1}-u$ & $n_{1}$ \\
$G_{j, b e f}$ & $t-u$ & $n_{2}-t+u$ & $n_{2}$ \\
Total & $t$ & $n_{1}+n_{2}-t$ & $n_{1}+n_{2}$ \\
\hline
\end{tabular}

Generally, chi-square test can be used when the sample size is more than 40 and the theoretical frequency is more than 5. (Note 5) The Fisher exact test can be applied when the sample size is less than 40.

The steps of the Fisher method are as follows:

(1) Calculating the actual frequency with the equation $T_{0}=\frac{1}{n}\left|u\left(n_{2}-t+u\right)-\left(n_{1}-u\right)(t-u)\right|$;

(2) Obtaining a series of tables by changing the value of $u$ with the constraint that the total value is invariable;

(3) Getting absolute value of $T_{i}$ which is the difference between the theoretical frequency and the actual data;

(4) Figuring out the probability $P_{i}$ corresponding to the fourfold table when $T_{0} \leq T_{i}$;

(5) Computing $P=\sum_{T_{i} \geq T_{0}} P_{i}$ to judge whether the null hypothesis $\pi_{1}=\pi_{2}$ is accepted.

Then, I get the results of the Fisher exact test. 
Table 8 . The results of the fisher test

\begin{tabular}{|c|c|c|c|c|c|c|c|c|c|}
\hline Break & Group & Subsamples & $u$ & $n_{1}-u$ & $t-u$ & $n_{2}-t+u$ & $n_{1}+n_{2}$ & $\begin{array}{l}\text { Monetary } \\
\text { aggregate }\end{array}$ & p-statistic \\
\hline \multirow{2}{*}{1} & $G_{1, a f t}$ & 2002:08-2003:05 & \multirow[t]{2}{*}{8} & \multirow[t]{2}{*}{2} & & & \multirow{2}{*}{27} & \multirow{2}{*}{ M2 } & \multirow{2}{*}{0.0183} \\
\hline & $G_{1, b e f}$ & 2001:04-2002:07 & & & 5 & 12 & & & \\
\hline \multirow{2}{*}{2} & $G_{2, a f t}$ & 2003:06-2004:05 & \multirow[t]{2}{*}{11} & \multirow[t]{2}{*}{1} & & & \multirow{2}{*}{29} & \multirow{2}{*}{ M1 } & \multirow{2}{*}{0.0020} \\
\hline & $G_{2, b e f}$ & 2002:01-2003:05 & & & 12 & 5 & & & \\
\hline \multirow{2}{*}{3} & $G_{3, a f t}$ & 2004:06-2006:02 & \multirow[t]{2}{*}{7} & \multirow[t]{2}{*}{14} & & & \multirow{2}{*}{33} & \multirow{2}{*}{ M2 } & \multirow{2}{*}{$5.2 \mathrm{E}-05$} \\
\hline & $G_{3, \text { bef }}$ & 2003:06-2004:05 & & & 11 & 1 & & & \\
\hline \multirow{2}{*}{4} & $G_{4, a f t}$ & 2005:08-2006:12 & \multirow[t]{2}{*}{12} & \multirow[t]{2}{*}{5} & & & \multirow{2}{*}{27} & \multirow{2}{*}{ M0 } & \multirow{2}{*}{0.0001} \\
\hline & $G_{4, b e f}$ & 2004:10-2005:07 & & & 2 & 8 & & & \\
\hline \multirow{2}{*}{5} & $G_{5, a f t}$ & 2007:03-2008:04 & \multirow[t]{2}{*}{12} & \multirow[t]{2}{*}{2} & & & \multirow{2}{*}{26} & \multirow{2}{*}{ M0 } & \multirow{2}{*}{0.0670} \\
\hline & $G_{5, b e f}$ & 2006:03-2007:02 & & & 10 & 2 & & & \\
\hline \multirow{2}{*}{6} & $G_{6, a f t}$ & 2009:02-2010:02 & \multirow[t]{2}{*}{7} & \multirow[t]{2}{*}{6} & & & \multirow{2}{*}{22} & \multirow{2}{*}{ M2 } & \multirow{2}{*}{0.0066} \\
\hline & $G_{6, \text { bef }}$ & 2008:05-2009:01 & & & 0 & 9 & & & \\
\hline 7 & $G_{7, a f t}$ & 2009:03-2010:02 & 7 & 5 & & & 22 & M1 & 00054 \\
\hline 1 & $G_{7, b e f}$ & 2008:05-2009:02 & & & 0 & 10 & 22 & $1 \mathrm{VHI}$ & 0.0004 \\
\hline 8 & $G_{8, a f t}$ & 2010:03-2011:07 & 12 & 5 & & & 25 & M0 & 00699 \\
\hline 0 & $G_{8, b e f}$ & 2009:07-2010:02 & & & 7 & 1 & 25 & & \\
\hline
\end{tabular}

For the breaks including breakpoints 1, 2, 3, 4, 6 and 7, the results of the Fisher exact test show that the null is rejected at the $1 \%$ or $5 \%$ critical level. After the emergence of the $1^{\text {st }}$ breakpoint, we are around $98.17 \%$ sure that the trend of CGPI during 2002:08-2003:05 is different from the situation of the period 2001:04-2002:07. This indicates that the structural change of broad money influences CGPI remarkably. As for the $2^{\text {nd }}$ breakpoint, there is about 99.80\% confidence that the growth rate during the period 2003:06-2004:05 is higher than that before the appearance of the break of narrow money. The p-statistic of Fisher exact test for $G_{3, a f t}$ and $G_{3, b e f}$ is 5.2E-05, which means the structural change of broad money occurring at the $3^{\text {rd }}$ breakpoint transforms the rising trend of CGPI into a falling one with more than $99.99 \%$ significant level. Opposite to the third break, the $4^{\text {th }}$ breakpoint which means the structural change of currency in circulation turns the falling trend of CGPI to a rising one soon. According to the $6^{\text {th }}$ and $7^{\text {th }}$ breakpoints occurring in the early 2009, the Fisher exact test illustrates that the structural changes of monetary aggregates by increasing M2 and M1 supply make CGPI go upward again. The p-statistics corresponding to the $5^{\text {th }}$ and $8^{\text {th }}$ breaks are $6.70 \%, 6.99 \%$ respectively. Therefore, the null is rejected at the $93.30 \%$ and $93.01 \%$ significant level.

The Fisher exact test getting the probabilities of $\pi_{1} \neq \pi_{2}$ for each pair of split samples coincides with the preliminary verification. Thus it obviously enhances the power of verification.

\section{Conclusion}

I restudy the impact of money supply on the overall price level because there is a common deficiency for the majority of literature investigating this issue. Only when all of variables including monetary aggregates and the overall price level are in the same order integration can the cointegration methodology be applied to discuss the topic mentioned above. However, this condition for using the cointegration technique and its derivatives doesn't always exist in the real macroeconomic world. The monthly data obtained from China's central bank illustrate that the time series of monetary aggregates during the period 1999:12-2012:04 are piecewise stationary rather than unit root processes. Moreover, CGPI is a unit root process. Therefore, the cointegration method and its derivatives are not suitable for my investigation.

According to the principles of structural change, the statistic characteristics would vary at the breakpoint between two segments of money stock which is a piecewise stationary series. The mutation is likely to affect the other 
macroeconomic series though a certain track. The study based on the theory of structural change shows that the overall price level is evidently influenced by the sudden changes corresponding to monetary aggregates.

Using monthly data during the period 1999:12-2012:04, the empirical tests of structural changes of monetary aggregates have shown that there are 6 breakpoints found at the $1 \%$ or $5 \%$ critical level and 2 beaks found at the $10 \%$ level. Furthermore, the test shows it is accurate to estimate CGPI trend with the information of each break. Therefore, it's an effective method applying structural change theory which is totally different from the cointegration methodology to resume debate regarding the relationship between the overall price level and money supply.

As to evaluation of the performance of monetary policy, the structural changes of monetary aggregates should be taken into account. One of the key targets of monetary policy is to make the overall price level stability, but the structural change of time series of money supply may result in the dramatic fluctuation of the price. Indeed, the impact from the structural change of money stock is likely to counteract the effect of other measures taken by the central bank. Consequently, the monetary policy may be invalid if the structural breaks of money supply are ignored. The study indicates that the steady control of money stock matters profoundly in dealing with the inflation or deflation in China. I am looking forward to the adoption of the structural break method by central bank or research institutes to evaluate the performance of monetary policy.

\section{Acknowledgements}

I acknowledge the research supports of Shantou University via Grants STF13012 and SR13002, I also thank the research support of the National Natural Science Foundation of China via 71071022.

\section{References}

Aksoy, Y., \& Piskorski, T. (2006). U.S. Domestic Money, Inflation and Output. Journal of Monetary Economics, 53, 183-197.

Andrews, D. W. K. (1993). Tests for Parameter Instability and Structural Change with Unknown Change Point. Econometrica, 61, 821-856.

Ben-David, D., Lumsdaine, R., \& Papell, D. (2003). Unit Roots, Postwar Slowdowns and Long-run Growth: Evidence from Two Structural Breaks. Empirical Economics, 28, 303-319.

Campbell, J. Y., \& Mankiw, N. G. (1987). Permanent and Transitory Components in Macroeconomic Fluctuations. American Economic Review, 77, 111-117.

Campbell, J. Y., \& Mankiw, N. G. (1988). Are Output Fluctuations Transitory. Quarterly Journal of Economics, 102, $857-880$.

Chow, G. C. (2002). China's Economic Transformation. Blackwell Publishers, Oxford.

Chow, G. C., \& Shen, Y. (2004). Money, Price Level and Output in the Chinese Macro Economy. CEPS Working Paper, No. 98, 1-21.

Dickey, D. A., \& Fuller, W. A. (1979). Distribution of the Estimators for Autoregressive Time Series with a Unit Root. Journal of the American Statistical Association, 74, 427-431.

Dickey, D. A., \& Fuller, W. A. (1981). Likelihood Ratio Statistics for Autoregressive Time Series with a Unit Root. Econometrica, 49, 1057-1072.

Djurić, P. M., Kay, S. M., \& Boudreaux-Bartels, G. F. (1992). Segmentation of Nonstationary Signals. Proceedings of the IEEE ICASSP, San Francisco, 5, 161-164.

Favara, G., \& Giordani, P. (2009). Reconsidering the Role of Money for Output, Prices and Interest Rates. Journal of Monetary Economics, 56, 419-430.

Kruse, R. (2009). A New Unit Root Test against ESTAR Based on a Class of Modified Statistics. Stat Papers, Springer-Verlag.

Lumsdaine, R. L., \& Papell, D. H. (1997). Multiple Trend Breaks and the Unit-root Hypothesis. The Review of Economics and Statistics, 79, 212-218.

McCandless, G. T., \& Weber, W. E. (1995). Some Monetary Facts. Federal Reserve Bank of Minneapolis Quarterly Review, 19, 2-11.

Narayan, P. K. (2005). The Structure of Tourist Expenditure in Fiji: Evidence from Unit-root Structural Break Tests. Applied Economics, 37, 1157-1161. 
Nelson, C. R., \& Plosser, C. (1982). Trends and Random Walks in Macroeconomic Time Series: Some Evidence and Implications. Journal of Monetary Economics, 10, 139-162.

Papell, D. H., \& Prodan, R. (2007). Restricted Structural Change and the Unit Root Hypothesis. Economic Inquiry, $45,834-853$.

Perron, P. (1988). Thends and Random Walks in Macroeconomic Time Series: Further Evidence from a New Approach. Journal of Economic Dynamics and Control, 12, 473-496.

Perron, P. (1989). The Great Crash, the Oil Price Shock, and the Unit-Root Hypothesis. Econometrica, 57, 1361-1401.

Perron, P. (1997). Further Evidence on Breaking Trend Functions in Macroeconomic Variables. Journal of Econometrics, 80, 355-385.

Quandt, R. E. (1960). Tests of the Hypothesis that a Linear Regression Obeys Two Separate Regimes. Journal of the American Statistical Association, 55, 324-330.

Shiller, R. J., \& Perron, P. (1985). Testing the Random Walk Hypothesis: Power Versus Frequency of Observation. Economics Letters, 18, 381-386.

Waingade, R. A. (2011). Money Supply and Inflation: A Historical Analysis. Journal of Monetary Economics, 9, $22-45$.

Wang, Z. Q., Tian Y. B., \& Wang S. Y. (2009). On structural change in China's import and export. Systems Engineering - Theory \& Practice, 2, 10-17.

Wasserfallen, W. (1986). Non-Stationarities in Macro-Economic Time Series - Further Evidence and Implications. Canadian Journal of Economics, 19, 498-510.

Zivot, E., \& Andrews, D. (1992). Further Evidence on the Great Crash, the Oil-Price Shock, and the Unit-Root Hypothesis. Journal of Business and Economic Statistics, 10, 251-270.

\section{Notes}

Note 1. Endogenous breakpoint actually occurred at $T \lambda+1$, where $T$ means sample size.

Note 2. $i=A, B, C$

Note 3. $\Lambda$ is a closed subset of $(0,1)$.

Note 4. $k_{\mathrm{inf}, \beta}^{i}$ are the significance values of the asymptotic distribution of $\inf _{\lambda_{\in \in \Lambda}} t_{\hat{\alpha}^{i}}(\lambda)$ with the critical values $\beta$.

Note 5. On the other hand, the modified chi-square test can be used if the sample size is less than 40 or the theoretical frequency is less than 5 but more than 1. 